\title{
Editorial
}

\section{Sustainable Lighting and Light Pollution: A Critical Issue for the Present Generation, a Challenge to the Future}

\author{
Georges Zissis \\ LAPLACE UMR 5213 CNRS-INPT-UT3, Université de Toulouse, 118 route de Narbonne, 31062 Toulouse, \\ CEDEX 9, France; georges.zissis@laplace.univ-tlse.fr
}

Received: 19 May 2020; Accepted: 29 May 2020; Published: 3 June 2020

\begin{abstract}
Human beings' poor night vision and primitive fear of the dark are reflected in an imperative need to use artificial light to illuminate their environment. Outdoor illumination undoubtedly contributes to the enhancement of practical opportunities for social and economic developments. Considered as a necessity, a means of security, and an attraction or valorization, city lighting growth has been literally exponential in the last half century. Beyond the financial and energy resources that it absorbs, the artificial lighting of urban spaces overflows its objective by polluting our nights to the point that, in our modern megacities, the stars disappear. Apart from the fact that stars are no longer visible, the scientific community is increasingly interested in the direct and indirect impacts of artificial lighting on biodiversity. In parallel, some studies have shown recently that stray light may have direct or indirect effects on human health and mood. The scope of this Special Issue, dedicated to the memory of Prof. Abraham Haim and Dr. Thomas Posch, is to put together a series of high-level papers treating light pollution in a holistic manner that goes from technological advances to policies, passing through impacts on biotopes and human health. Beyond its evident scientific interest, this Special Issue is also contributing to awareness raising, aimed at decision- and policy-makers.
\end{abstract}

Keywords: light pollution measurement and modelling; light pollution impact on fauna and flora; light pollution impact on human health; policies to prevent/limit light pollution and territorial management; best practices for street lighting with low impact on light pollution; smart lighting and light pollution

The human being is not a night animal, even if the night sky has fascinated our species since the dawn of our existence. Our poor night vision and our primitive fear of the dark are reflected in an imperative need to use artificial light to illuminate our environment. Here, the term "artificial light" refers to man-made night-time light. The power to artificially override the natural cycle of light and dark is recent, but decisive, event for human society. For sure, outdoor illumination undoubtedly provides enhanced practical opportunities for social life development and contributes to an extensive range of evening and night-time activities that would otherwise be difficult, if not impossible, without artificial light.

Considered as a necessity, a means of security, and an attraction or valorization, city lighting growth has been literally exponential, especially since World War II. The phenomenal rise of public lighting is manifested today by at least 100 million lighting points illuminating our cities worldwide, whose annual electricity consumption would represent, roughly, more than $200 \mathrm{TWh}$. Further, lighting constitutes up to $25 \%$ of the budget of rural small-size cites, corresponding to roughly $50 \%$ of their electricity bill. This uncontrollable growth is no longer sustainable and a drastic reduction in energy consumption must be imposed. 
Beyond the financial and energy resources that it absorbs, the artificial lighting of urban spaces overflows its objective by polluting our nights to the point that, in our modern megacities, the stars disappear from the night sky when, just 100 years ago, the milky way could be observed from almost everywhere. However, the loss of the night skies has happened gradually over the course of the last century and this has resulted in a collective ignorance of the degradation, about which none but astronomers complained about for a long time.

Apart from the fact that stars are no longer visible, the scientific community is increasingly interested in the direct and indirect impacts of artificial lighting on biodiversity. We know that, for more than 100 years now, all living organisms have evolved varying degrees of sensitivity to light. Light stimulates hormone production, regulating circadian rhythms in all living species, and it also influences phototropism in plants.

In fact, the biological adaptation of all animal species to natural light conditions (sun, moon, and stars) has evolved over billions of years in all animal species. Paul Beier underlined that "most nocturnal mammals react to increasing moonlight by reducing their use of open areas, restricting foraging activity and movements, reducing total duration of activity, or concentrating foraging and longer movements during the darkest periods of night." [1]

Several experimental studies have shown that artificial light at night-time disturbs ecosystems and could play a significant role in the decline of species whose roles in the ecosystem, already weakened by human presence, are not yet fully known. There are some examples, among many others:

Sea turtle hatchlings emerge from the nest at night and use visual cues to direct themselves towards the brightest and lowest horizon, eventually leading them to the sea. Night-light pollution could alter the cues perceived, disorienting the fragile hatchlings [2].

Seabirds of the order Procellariformes (albatrosses, petrels ... ) are known to be highly affected by light pollution near their breeding colonies. The prime and most serious impact is related to the abandonment of colonies [3]. The second impact relates to the disorienting effect that light pollution has on immature individuals that disperse for the first time from their colonies [4].

Kerbiriou et al. showed that the loss or the gain in bat activity when lamp types (i.e., spectrum) are switched strongly depends on the initial and the new lamp intensities. Their results stress the need to consider simultaneously the effects of changes in different light characteristics when street lighting changes [5].

We know that invertebrates make up the majority of biodiversity on earth and are vital to ecosystems. Artificial lighting attracts large numbers of a wide range of invertebrates, but moths are perhaps best known for this behavior [6]. UV, green, and blue light, which have short wavelengths and high frequencies, are best discriminated by most insects and are highly attractive to them [7].

Current research highlights the importance of artificial light with smaller wavelengths in attracting moths, yet the effect of the spectral composition of artificial light on species' richness and on the abundance of moths has not been studied systematically [8]. Further, the role of moths in pollination processes is not fully known.

In parallel, some studies have recently shown that stray light may have direct or indirect effects on human health and mood. As an example, people report negative health impacts from sleep disturbances due to light intrusion into their homes. In addition, human health problems have been associated with exposure to artificial light at night, inhibiting the production of melatonin, which is associated with the incidence of certain breast cancers [9]. In any case, even low levels of illuminance in the blue region of the light spectrum may disrupt melatonin secretion with catastrophic effects to sleep-wake cycles. Further, artificial lighting may also result in night-time glare, including disability glare, which affects driving and pedestrian safety. However, its detection and quantification are generally subjective and relative to existing conditions. Further, it is often said that outdoor lighting can reduce criminality in modern cities; however, there is no systematic study that can provide an evidence to this "urban legend". 
Thus, scientific evidence highlighting the negative impacts of artificial lighting in connection with strong actions from the associates of militant people contributed to a spectacular increase in awareness at a political level in many countries. As a consequence, light pollution is now taken into consideration in more and more national environmental protection and territorial development policies. In addition, some locations are particularly sensitive to light pollution and lighting schemes, and these areas should be carefully planned around to avoid negatively affecting fragile ecosystems.

Globally, today we can say with certitude that artificial light in the wrong place or at the wrong time is light pollution. Artificial light has the potential to significantly disrupt ecosystems and natural light and dark patterns. Light pollution, unlike other forms of contamination and waste, remains largely overlooked and unregulated in many countries. It is often exacerbated by excessive, misdirected, or obtrusive uses of light that is difficult to explain today. It is necessary to measure light pollution, quantify the impact on biodiversity, build reliable and robust simulation tools that allow us to predict the impact of new technologies in light pollution, and open questions that need rapid and precise answers. Today, we know that even if a part of light pollution (called usually "sky glow") is unavoidable due the diffusion of light in the atmosphere (linked mainly to the reflection of moisture and very fine particulate matter in suspension), most of the pollution is coming from poor lighting design, often exacerbated by poor installation and maintenance. That part is avoidable, but initial costs for high-quality lighting systems may rise rapidly to the point of become prohibitive for countries with developing economies. On the other hand, in developed economies, the private lighting of external space is a growing cause for concern, because it is rather difficult to regulate with policies. Population awareness raising is most likely the solution here.

The scope of this Special Issue is to put together a series of high-level papers treating light pollution in a holistic manner that goes from technological advances to policies, passing through the impacts on biotopes and human health. Nine excellent papers are included in this Special Issue, placing it in a prime position in today's literature in the domain of light pollution. Beyond evident scientific interest, this Special Issue is also contributing to awareness raising, aimed at decision- and policy-makers.

Funding: This research was funded partially by the Conseil Régional Occitanie (FEDER) grant number 19005652/MP0021697-LightCampus.

Acknowledgments: This Special Issue is dedicated to the memory of Abraham Haim and Thomas Posch who recently left us unexpectedly. They continue to inspire, by their example and dedication, our work for the prevention of light pollution. By dedicating this paper to them, we would like to acknowledge their major contribution to our community.

Conflicts of Interest: The author declares no conflict of interest.

\section{References}

1. Beirer, P. Effects of Artificial Night Lighting on Terrestrial Mammals. In Ecological Consequences of Artificial Night Lighting; Rich, C., Longcore, T., Eds.; Island Press: Washington, DC, USA, 2006.

2. Dimitriadis, C.; Fournari-Konstantinidou, I.; Sourbès, L.; Koutsoubas, D.; Mazaris, A.D. Reduction of sea turtle population recruitment caused by nightlight: Evidence from the Mediterranean region. Ocean Coast. Manag. 2018, 153, 108-115. [CrossRef]

3. Sultana, J.; Borg, J.J.; Gauci, C.; Falzon, V. The Breeding Birds of Malta; Bird Life Malta: Ta' Xbiex, Malta, 2011.

4. Le Corre, M.; Ollivier, A.; Ribes, S.; Louventin, P. Light-induced mortality of petrels: A 4-year study from Reunion Island (Indian Ocean). Biol. Conserv. 2002, 105, 93-102. [CrossRef]

5. Kerbiriou, C.; Barré, K.; Mariton, L.; Pauwels, J.; Zissis, G.; Robert, A.; Le Viol, I. Switching LPS to LED Streetlight may Dramatically Reduce Activity and Foraging of Bats. Diversity 2020, 12, 165. [CrossRef]

6. Frank, K.D. Impact of outdoor lighting on moths: An assessment. J. Lepidopterists' Soc. 1988, 42, 63-93.

7. Bruce-White, C.; Shardlow, M. A Review of the Impact of Artificial Light on Invertebrates; Buglife-The Invertebrate Conservation Trust: Peterborough, UK, 2011. 
8. Van Langevelde, F.; Ettema, J.A.; Donners, M.; WallisDeVries, M.F.; Groenendijk, D. Effect of spectral composition of artificial light on the attraction of moths. Biol. Conserv. 2011, 144, 2274-2281. [CrossRef]

9. IARC. IARC Monographs Programme Finds Cancer Hazards Associated with Shiftwork, Painting and Firefighting; Press Release No. 180, 5 December 2007; International Agency for Research on Cancer: Lyon, France, 2007.

(C) 2020 by the author. Licensee MDPI, Basel, Switzerland. This article is an open access article distributed under the terms and conditions of the Creative Commons Attribution (CC BY) license (http://creativecommons.org/licenses/by/4.0/). 